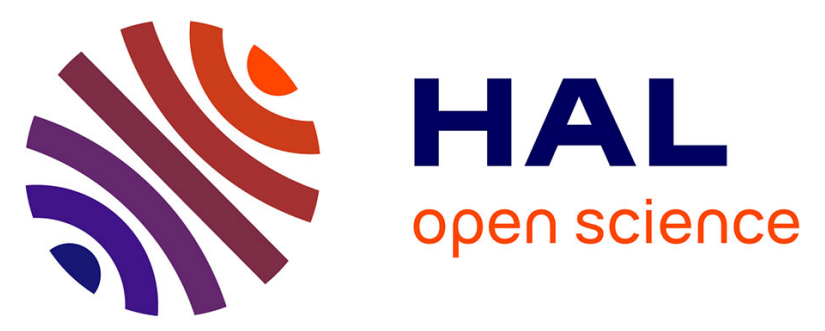

\title{
A "reverse interrupter": the novel molecular design of a fluorescent photochromic DTE-based bipyridine
}

Vincent Aubert, Eléna Ishow, Fatima Ibersiene, Abdou Boucekkine, J. A. Gareth Williams, Loic Toupet, Rémi Métivier, Keitaro Nakatani, Véronique Guerchais, Hubert Le Bozec

\section{To cite this version:}

Vincent Aubert, Eléna Ishow, Fatima Ibersiene, Abdou Boucekkine, J. A. Gareth Williams, et al.. A "reverse interrupter": the novel molecular design of a fluorescent photochromic DTE-based bipyridine. New Journal of Chemistry, 2009, 33 (6), pp.1320-1323. 10.1039/b823113c . hal-00442461

\section{HAL Id: hal-00442461 https://hal.science/hal-00442461}

Submitted on 12 Sep 2013

HAL is a multi-disciplinary open access archive for the deposit and dissemination of scientific research documents, whether they are published or not. The documents may come from teaching and research institutions in France or abroad, or from public or private research centers.
L'archive ouverte pluridisciplinaire HAL, est destinée au dépôt et à la diffusion de documents scientifiques de niveau recherche, publiés ou non, émanant des établissements d'enseignement et de recherche français ou étrangers, des laboratoires publics ou privés. 


\title{
A "reverse interrupter": the novel molecular design of a fluorescent photochromic DTE-based bipyridine $\dagger$
}

\author{
Vincent Aubert, ${ }^{a}$ Elena Ishow,${ }^{b}$ Fatima Ibersiene, ${ }^{a}$ Abdou Boucekkine, ${ }^{a}$ \\ J. A. Gareth Williams, ${ }^{c}$ Loic Toupet, ${ }^{d}$ Rémi Métivier, ${ }^{b}$ Keitaro Nakatani, ${ }^{b}$ \\ Véronique Guerchais* ${ }^{* a}$ and Hubert Le Bozec ${ }^{* a}$
}

Received (in Montpellier, France) 23rd December 2008, Accepted 30th January 2009

First published as an Advance Article on the web 12th February 2009

DOI: $10.1039 / \mathbf{b 8 2 3 1 1 3 c}$

\begin{abstract}
An original design of a fluorescent dithienylethene (DTE)-based bipyridine, where donor (D) and acceptor (A) groups are located on the same thiophene ring of the DTE unit, is reported; in non-polar solvents, UV or visible excitation triggers a photochromic reaction, disrupting the conjugation and quenching the fluorescence.
\end{abstract}

Fluorescent switching systems containing photochromic molecules have attracted significant attention on account of their potential uses as optical memory media and photoswitchable devices. ${ }^{1}$ Most systems offering the photomodulation of luminescence involve a photochrome covalently linked to an organic ${ }^{2}$ or metal-organic ${ }^{3}$ fluorophore, wherein the luminescence is regulated by an intramolecular energy transfer from the excited fluorophore to the photochromic unit. In contrast, little attention has been devoted to luminescent photoswitches based on donor-bridge-acceptor (D- $\pi-A)$ derivatives, in which the photochromic unit is a part of the $\pi$-conjugated bridge. ${ }^{4}$

We have previously shown that 2,2'-bipyridines featuring $\pi$-donor-conjugated substituents are good building blocks for the construction of metal complexes with very large non-linear optical responses and interesting luminescent properties, which are governed by strong intra-ligand charge transfer (ILCT) transitions. ${ }^{5}$ In the course of our continuing exploration of such systems and the search for the photomodulation of these properties, we have recently incorporated a dithienylethene (DTE) unit into a donor-substituted styrylbipyridine ligand, allowing the preparation of the first example of metalcontaining photochromic bipyridine ligands displaying an efficient switching of the NLO responses (Scheme 1(a)). ${ }^{6}$

\footnotetext{
${ }^{a}$ Sciences Chimiques de Rennes UMR 6226, CNRS-Université de Rennes 1, Campus de Beaulieu, 35042 Rennes, France.

E-mail:lebozec@univ-rennes1.fr,veronique.guerchais@univ-rennes1.fr; Fax: + 33 223236939; Tel: + 33223236544

${ }^{b}$ Laboratoire de Photophysique et Photochimie Moléculaire, UMR

CNRS 8531, ENS Cachan, 94235 Cachan, France

' Department of Chemistry, University of Durham, South Road, Durham, UK DH1 3LE

${ }^{d}$ Groupe Matière Condensée, UMR 6626 CNRS, Université de Rennes 1, Campus de Beaulieu, 35042 Rennes, France

$\dagger$ Electronic supplementary information (ESI) available: Experimental procedures and characterizations, details of the crystallographic structure of 1(o,o), and DFT calculations. CCDC 640444. For ESI and crystallographic data in CIF or other electronic format see DOI: $10.1039 / \mathrm{b} 823113 \mathrm{c}$
}

However, these free bipyridine ligands, in which the donor (D) and acceptor (A) groups are located at each end of the DTE unit, are not emissive under ambient conditions, neither in the open nor closed forms. Thus, as an alternative way to obtain a fluorescent photoswitch, we sought to design a push-pull chromophore featuring $\mathbf{D}$ and $\mathbf{A}$ moieties located at the 2- and 5-positions of the same thiophene ring of the DTE unit (Scheme 1(b)), rather than them being located on two different thiophene rings. ${ }^{4,7}$ In this so-called "reverse interrupter", $\pi$-conjugation between $\mathbf{A}$ and $\mathbf{D}$ is efficient only when the DTE unit is in its open form ("ON" state), whereas in the closed ring isomer ("OFF" state), the formation of a tetrahedral $\mathrm{sp}^{3}$ center at the $\mathrm{C}^{2}$ carbon disconnects the $\mathbf{D}$ and A parts of the molecule. In these systems, it was anticipated that the rupture of the intramolecular charge transfer accompanying the photoisomerization process would allow modulation of the emission properties of the chromophore.

As a first approach, we wish to disclose our preliminary results in the synthesis, and photochromic and photophysical studies of reverse interrupter $\mathbf{1}$, containing dimethylaminophenyl and vinylbipyridine moieties as the $\mathbf{D}$ and $\mathbf{A}$ end groups, respectively (Scheme 2). We show that the photochromic reaction can be triggered upon excitation with UV and visible light. In addition, this process, which can itself be switched on or off according to the polarity of the solvent, allows an efficient modulation of the fluorescence.

Substituted 4,4'-vinyl-2,2'-bipyridine derivatives are accessible via a Wadsworth-Emmons reaction of bipyridine-bis (phosphonate) 7 and the appropriate aldehyde in the presence of a base. We have used this approach to prepare compound 1 (Scheme 3). The two distinct thienyl fragments, 3 and $\mathbf{4}$, were first prepared independently. The p-dimethylaminophenyl

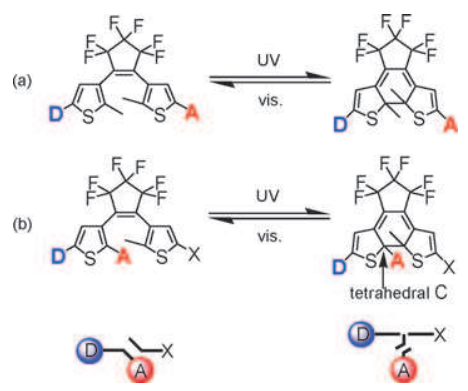

Scheme 1 Schematic representation of normal (a) and "reverse" (b) push-pull interrupters. 


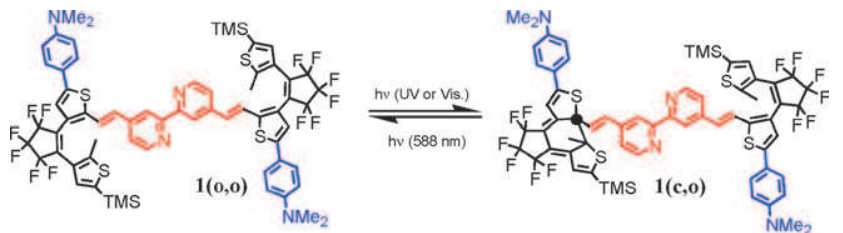

Scheme 2 The photochromic reaction of $\mathbf{1}$.

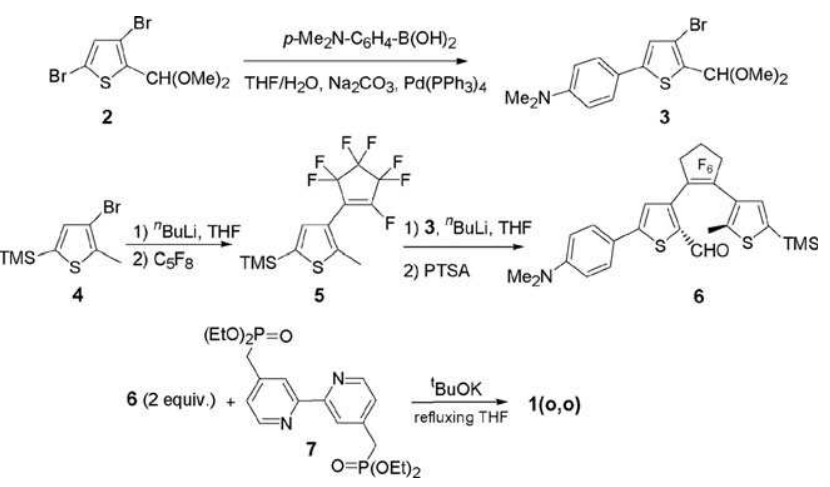

Scheme 3 The synthesis of $\mathbf{1}(\mathbf{0 , 0})$.

group was introduced onto 3,5-dibromothiophene-2dimethylacetal 2 through a Suzuki cross-coupling reaction to give $\mathbf{3}$. The second thienyl derivative, $\mathbf{4}$, bearing a protecting trimethylsilyl group, was reacted with octafluorocyclopentene $\left(\mathrm{C}_{5} \mathrm{~F}_{8}\right)$ using a common procedure to yield $\mathbf{5}$. Thienyl derivative 3 was treated with $n$-BuLi, and then coupled with 5 to afford $\mathbf{6}$. Eventually, the reaction of $\mathbf{6}$ with $\mathbf{7}$ in the presence of $t$-BuOK in refluxing THF afforded $\mathbf{1 ( 0 , 0 )}$ as its $E, E$ isomer in a $50 \%$ yield.

Single crystals of $\mathbf{1}(\mathbf{0}, \mathbf{0})$ were grown upon slow evaporation of a $\mathrm{CH}_{2} \mathrm{Cl}_{2}$ solution. The X-ray structure (Fig. 1) reveals an antiparallel conformation, in which the vinylbipyridine at the 2-position of one thiophene ring and the methyl group at the $2^{\prime}$-position are pointing in opposite directions. In addition, the distance between the two reactive carbon atoms (C-C $3.587 \AA$ ) is appropriate for a cyclization process. ${ }^{7 a, 8}$ The geometry optimization performed using Gaussian 03 was in good agreement with the experimental structure (see ESI, Fig. S1 $\dagger$ ).

The UV-vis absorption spectrum of $\mathbf{1}(\mathbf{0 , 0})$ in cyclohexane (Fig. 2, Table 1) displays an intense band at $\lambda=326 \mathrm{~nm}$

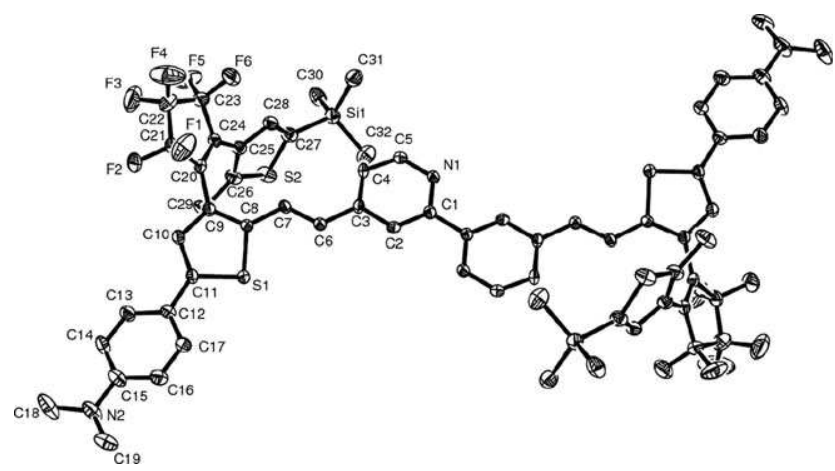

Fig. 1 An ORTEP plot for 1(o,o) drawn with thermal ellipsoids at the $50 \%$ probability level. Hydrogen atoms are omitted for clarity. The molecule lies about an inversion centre.

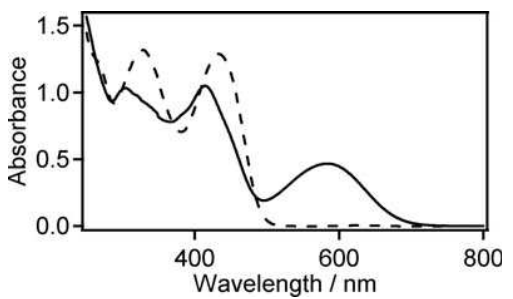

Fig. 2 UV-vis absorption spectra of $\mathbf{1}$ in cyclohexane solution in $\left(3.4 \times 10^{-5} \mathrm{M}\right)$ : open-ring isomer (--) and photostationary state (-).

Table 1 Absorption and emission data of 1

\begin{tabular}{lllll}
\hline Solvent & $\begin{array}{l}\lambda_{\text {abs }} / \mathrm{nm}\left(\varepsilon / \mathrm{M}^{-1} \mathrm{~cm}^{-1}\right) \\
\text { Open form }\end{array}$ & $\begin{array}{l}\lambda_{\text {abs }} / \mathrm{nm}^{a} \\
\text { PSS }^{a}\end{array}$ & $\begin{array}{l}\lambda_{\mathrm{em}} / \mathrm{nm}^{b} \\
\text { Open form }\end{array}$ & $\begin{array}{l}\Phi_{\mathrm{f}}(\tau / \mathrm{ns}) \\
\text { Open form }\end{array}$ \\
\hline Cyclohexane & $326(37400)$, & 304, & 535 & 0.22 \\
& $433(37000)$ & 414, & & \\
$\mathrm{CH}_{2} \mathrm{Cl}_{2}$ & $333(37700)$, & 584 & 640 & $0.38(4.2)$ \\
$\mathrm{EPA}^{c}$ & $446(36500)$ & - & & \\
& $330(34000)$, & - & 664 & $-(3.7)$
\end{tabular}

${ }^{a}$ After irradiation at $313 \mathrm{~nm} .{ }^{b} \lambda_{\mathrm{exc}}=313$ or $430 \mathrm{~nm} .{ }^{c} \mathrm{EPA}=$ ether/ pentane/isopropanol.

attributed to the ${ }^{1}$ IL $\left(\pi \rightarrow \pi^{*}\right)$ transition of the DTE unit. In addition, 1(o,o) also shows another broad band at $\lambda=435 \mathrm{~nm}$ that can be ascribed to an intramolecular charge transfer (ICT) transition, which compares well with that of related 4,4'-bis(dibutylaminothienylvinyl)-2,2'-bipyridine $\left(\lambda_{\max }=\right.$ $443 \mathrm{~nm}$ in $\left.\mathrm{CH}_{2} \mathrm{Cl}_{2}\right) .{ }^{9}$ The assignments of these two bands were also supported by theoretical calculations. The contour plots depicted in Fig. 3 show that the HOMO is predominantly localized on the dimethylaminophenylthiophene, while the LUMO is delocalized over the vinylpyridine and the $\mathrm{C}_{5} \mathrm{~F}_{6}$ fragments, and the LUMO +1 mainly corresponds to the $\pi^{*}$ orbital of the $\mathrm{C}_{5} \mathrm{~F}_{6}$ fragment. In addition, the electronic absorption spectrum calculated by TD-DFT nicely matches that observed experimentally, indicating that the two lowest transitions are dominated by excitations from the HOMO to the LUMO and the LUMO + 1, respectively (see ESI $\dagger$ ).

Compound $\mathbf{1}(\mathbf{0 , 0})$ displays strong fluorescence in solution at $298 \mathrm{~K}\left(\lambda_{\text {em }}=535 \mathrm{~nm}\right.$ in cyclohexane $)$ when excited at 430 or $313 \mathrm{~nm}$. It is interesting to note that the emission quantum yield $\left(\Phi_{\mathrm{f}}=0.22\right)$ is independent of the excitation wavelength. Increasing the polarity of the solvent leads to a very pronounced red shift of the emission band $\left(\lambda_{\mathrm{em}}\left(\mathrm{CH}_{2} \mathrm{Cl}_{2}\right)=\right.$ $\left.640 \mathrm{~nm} ; \lambda_{\mathrm{em}}(\mathrm{EPA})=664 \mathrm{~nm}\right)$, consistent with charge-transfer character for the fluorescent singlet excited state. (Fig. 4, Table 1).

The photochromic behaviour of $\mathbf{1 ( 0 , 0 )}$ was followed by ${ }^{1} \mathrm{H}$ NMR and UV-visible absorption spectroscopy in cyclohexane and $\mathrm{CH}_{2} \mathrm{Cl}_{2}$ solutions. The photoisomerization was found to be highly solvent-dependent. In cyclohexane, $\mathbf{1}(\mathbf{o , o})$ undergoes a photocyclization process upon irradiation in either of the two main absorption bands at $\lambda=313$ or $436 \mathrm{~nm}$. On the basis of ${ }^{1} \mathrm{H}$ NMR spectroscopy in $d^{12}$-cyclohexane (see ESI $\dagger$ ), the photoproduct was assigned as closed-ring $\mathbf{1}(\mathbf{c}, \mathbf{0})$, in which one of the two DTE units is in its closed form ( $80 \%$ conversion). ${ }^{10}$ Fig. 2 displays a characteristic absorption band at $584 \mathrm{~nm}$ 


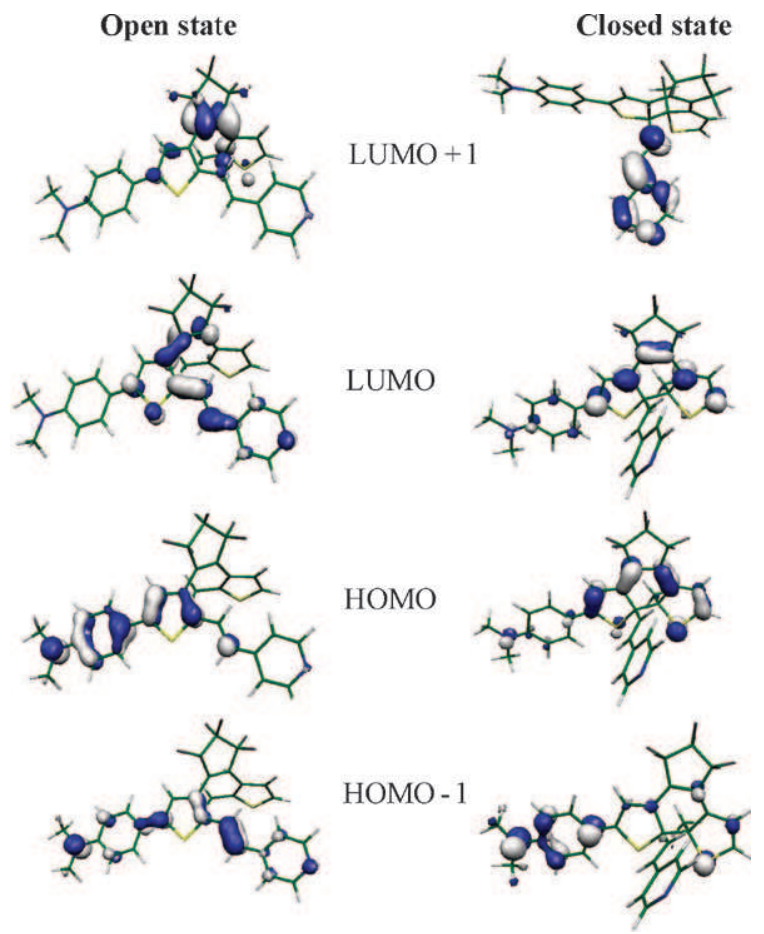

Fig. 3 Frontier orbital representations of the open and closed forms of the pyridine fragments of $\mathbf{1}$.

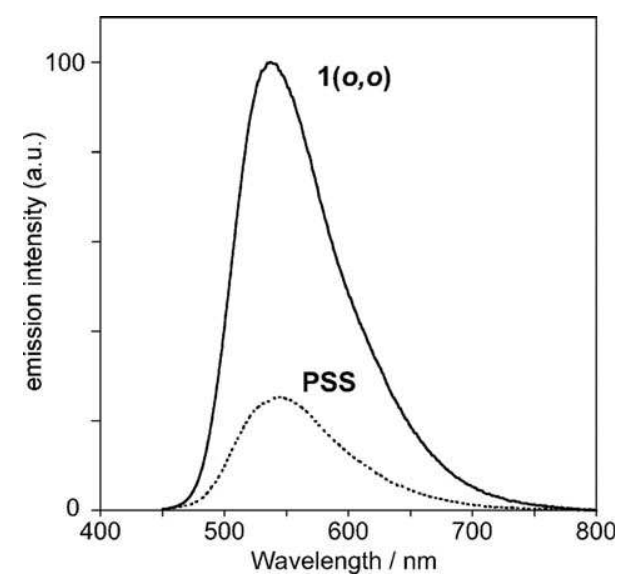

Fig. 4 Emission spectra of $\mathbf{1}$ at $298 \mathrm{~K}$ in cyclohexane.

attributed to the closed DTE unit, along with another band at $414 \mathrm{~nm}$. As shown in Fig. 3, the HOMO and LUMO of the closed pyridine fragment are mainly localized on the DTE unit, whereas the HOMO -1 and LUMO +1 are localized on the dimethylaminophenyl and vinylpyridine groups, respectively. The calculated electronic spectrum (see ESI $\dagger$ ) is in good agreement with the experimental spectrum, showing that the two bands essentially correspond to the HOMO $\rightarrow$ LUMO and HOMO $-1 \rightarrow$ LUMO excitations, respectively. Irradiation of the absorption band of the closed form at $588 \mathrm{~nm}$ resulted in the quantitative regeneration of the open isomer. The cyclization and cycloreversion quantum yields were determined to be 0.081 irradiating at $436 \mathrm{~nm}$ and 0.016 irradiating at $588 \mathrm{~nm}$, respectively. Strikingly, in contrast to its behaviour in cyclohexane, the irradiation of $\mathbf{1 ( o , o )}$ in $\mathrm{CH}_{2} \mathrm{Cl}_{2}$ at $313 \mathrm{~nm}$ did not trigger the photocyclization process, while a strong emission at $640 \mathrm{~nm}$ was still observed. The excitation spectrum registered at this wavelength closely matched the absorption spectrum, confirming that absorbed light at any wavelength is efficiently transferred to the ICT state. Relaxation from the ${ }^{1} \mathrm{IL}$ (DTE) state to the emissive ICT state leads to the inhibition of the DTE-based ring closure reaction. This behavior is driven by the lower-lying CT excited state, which is significantly stabilized in $\mathrm{CH}_{2} \mathrm{Cl}_{2}$, whereas in less polar solvents like cyclohexane, the fluorescence $\left(\Phi_{\mathrm{f}}=0.22, \lambda_{\mathrm{exc}}=313\right.$ or $\left.430 \mathrm{~nm}\right)$ and photoisomerization processes appear to be competitive.

Upon conversion to the photostationary state (PSS) by irradiation of a cyclohexane solution of $\mathbf{1}(\mathbf{0 , 0})$ at $430 \mathrm{~nm}$, the "apparent" fluorescence quantum yield decreases to 0.03 (Fig. 4). The residual emission is attributed to the remaining open form $\mathbf{1}(\mathbf{o}, \mathbf{0})$ present in the PSS. The decrease in fluorescence intensity is photocontrolled by (i) the disruption of the $\mathrm{D}-\pi-\mathrm{A}$ conjugation and (ii) an intramolecular energy transfer of the excited open pyridine fragment to the acceptor closedring DTE pyridine moiety of $\mathbf{1}(\mathbf{c}, \mathbf{o})$.

In conclusion, we have synthesized an original fluorescent photochromic bipyridine by functionalizing one thiophene ring of a DTE fragment. This novel chromophore will open up new perspectives for the elaboration of metal-based photoswitches.

This work was supported by The Agence National de la Recherche (ANR Blan08-1-308898), COST D035-0010-05 and Région Bretagne (SIE 211-B3-11). F. I. thanks the Université des Sciences et de la Technologie Houari Boumedienne (Alger) for a sabbatical leave.

\section{Experimental}

\section{Preparation of 6}

To a solution of 3 (192 mg, $0.5 \mathrm{mmol})$ in $15 \mathrm{~mL}$ of THF that had been cooled to $-78{ }^{\circ} \mathrm{C}$ was added, dropwise, $n$ - $\mathrm{BuLi}$ $(2.16 \mathrm{M}$ in hexane, $0.25 \mathrm{~mL}, 0.54 \mathrm{mmol})$. After stirring at $-78{ }^{\circ} \mathrm{C}$ for $1 \mathrm{~h}$, a solution of $5(196 \mathrm{mg}, 0.54 \mathrm{mmol})$ in $10 \mathrm{~mL}$ of THF was added to the reaction mixture. After stirring at $-78{ }^{\circ} \mathrm{C}$ for $1 \mathrm{~h}$ and at room temperature for $16 \mathrm{~h}$, the reaction mixture was hydrolyzed with water $(25 \mathrm{~mL})$, and the solvent removed in vacuo. The residue was extracted with $\mathrm{CH}_{2} \mathrm{Cl}_{2}(2 \times 30 \mathrm{~mL})$ and then dried over $\mathrm{MgSO}_{4}$. After evaporation of the solvent, the residual orange oil was dissolved in $20 \mathrm{~mL}$ of THF, then PTSA ( $p$-toluenesulfonic acid) $(20 \mathrm{mg}$, $0.1 \mathrm{mmol}$ ), and finally a few drops of water were added. After stirring at $40{ }^{\circ} \mathrm{C}$ for $16 \mathrm{~h}$, the solvent was removed and the oil purified by column chromatography $\left(\mathrm{SiO}_{2}\right.$, pentane- $\left.\mathrm{CH}_{2} \mathrm{Cl}_{2} 1: 1\right)$ to give a red powder $(179 \mathrm{mg}, 60 \%) .{ }^{1} \mathrm{H}$ NMR $(500 \mathrm{MHz}$, $\left.\mathrm{CDCl}_{3}\right): \delta 9.40(\mathrm{~s}, 1 \mathrm{H}, \mathrm{CHO}), 7.55\left(\mathrm{~d},{ }^{3} J=8.9 \mathrm{~Hz}, 2 \mathrm{H}, \mathrm{C}_{6} \mathrm{H}_{4}\right)$, 7.28 (s, $1 \mathrm{H}$, thio), $7.10\left(\mathrm{~s}, 1 \mathrm{H}\right.$, thio), $6.74\left(\mathrm{~d},{ }^{3} J=8.9 \mathrm{~Hz}, 2 \mathrm{H}\right.$, $\left.\mathrm{C}_{6} \mathrm{H}_{4}\right), 3.07\left(\mathrm{~s}, 6 \mathrm{H}, \mathrm{NMe}_{2}\right), 2.08(\mathrm{~s}, 3 \mathrm{H}, \mathrm{Me})$ and 0.30 (s, 9H, TMS). $\left.{ }^{13} \mathrm{C}^{1} \mathrm{H}\right] \mathrm{NMR}\left(125 \mathrm{MHz}, \mathrm{CDCl}_{3}\right): \delta 180.5$, 155.6, 151.5, 147.4, 140.1, 137.2, 135.7, 133.7, 127.5, 124.7, 121.7, 119.7, 112.1, 40.2, 30.3, 14.4 and -0.3 . Anal. calc. for $\mathrm{C}_{26} \mathrm{H}_{25} \mathrm{~F}_{6} \mathrm{~N}_{1} \mathrm{~S}_{2} \mathrm{Si} \cdot 0.5 \mathrm{CH}_{2} \mathrm{Cl}_{2}$ : C, 54.46; H, 4.44; N, 2.33 . 
Found: C, 54.80; H, 4.70; N, 2.30\%. HRMS: $m / z=573.1069$ $[\mathrm{M}]^{+}$(calc. for $\mathrm{C}_{26} \mathrm{H}_{25} \mathrm{~F}_{6} \mathrm{~N}_{1} \mathrm{~S}_{2} \mathrm{Si}=573.1051$ ).

\section{Preparation of $1(0,0)$}

To a THF solution of $6(350 \mathrm{mg}, 0.64 \mathrm{mmol})$ and $7(126 \mathrm{mg}$, $0.28 \mathrm{mmol})$ was added $t$-BuOK $(77 \mathrm{mg}, 0.70 \mathrm{mmol})$. After refluxing overnight, the reaction mixture was hydrolyzed with water, and the organic phase washed with a saturated solution of $\mathrm{Na}_{2} \mathrm{CO}_{3}$, dried over $\mathrm{MgSO}_{4}$ and evaporated in vacuo. The residue was recrystallized from a $\mathrm{CH}_{2} \mathrm{Cl}_{2} /$ pentane mixture at $-20{ }^{\circ} \mathrm{C}$ to give $\mathbf{1}(\mathbf{o , o})$ as a red powder $(180 \mathrm{mg}$, $50 \%) .{ }^{1} \mathrm{H}$ NMR $\left(500 \mathrm{MHz}, \mathrm{CDCl}_{3}\right): \delta 8.63\left(\mathrm{~d},{ }^{3} J=5.1 \mathrm{~Hz}\right.$, $\left.1 \mathrm{H}, \mathrm{Py}^{6}\right), 8.26\left(\mathrm{~s}, 1 \mathrm{H}, \mathrm{Py}^{3}\right), 7.53\left(\mathrm{~d},{ }^{3} J=8.9 \mathrm{~Hz}, 2 \mathrm{H}, \mathrm{C}_{6} \mathrm{H}_{4}\right)$, 7.25 (s, $1 \mathrm{H}$, thio), 7.23 (s, $1 \mathrm{H}$, thio), 7.17 (dd, ${ }^{3} J=5.1 \mathrm{~Hz}$ and $\left.{ }^{4} J=1.6 \mathrm{~Hz}, 1 \mathrm{H}, \mathrm{Py}{ }^{5}\right), 6.94\left(\mathrm{~d},{ }^{3} J=15.9 \mathrm{~Hz}, 1 \mathrm{H},=\mathrm{CH}\right), 6.77$ $\left(\mathrm{d},{ }^{3} J=8.9 \mathrm{~Hz}, 2 \mathrm{H}, \mathrm{C}_{6} \mathrm{H}_{4}\right), 6.71\left(\mathrm{~d},{ }^{3} J=15.9 \mathrm{~Hz}, 1 \mathrm{H},=\mathrm{CH}\right)$, 3.05 (s, 6H, $\left.\mathrm{NMe}_{2}\right), 1.99$ (s, 3H, Me) and 0.03 (s, 9H, TMS). ${ }^{13} \mathrm{C}\left[{ }^{1} \mathrm{H}\right] \mathrm{NMR}\left(125 \mathrm{MHz}, \mathrm{CDCl}_{3}\right): \delta 156.4,150.7,149.4,147.8$, $147.5,146.2,144.7,139.5,138.5,133.5,128.4,126.9,126.5$, 125.6, 123.5, 120.9, 120.7, 119.6, 119.0, 112.3, 40.3, 14.5 and -0.6. Anal. calc. for $\mathrm{C}_{64} \mathrm{H}_{58} \mathrm{~F}_{12} \mathrm{~N}_{4} \mathrm{~S}_{4} \mathrm{Si}_{2}: \mathrm{C}, 59.33 ; \mathrm{H}, 4.51 ; \mathrm{N}$, 4.32. Found: $\mathrm{C}, 59.87 ; \mathrm{H}, 4.86$; N, 4.79\%. HRMS: $m / z=$ $1294.2875[\mathrm{M}]^{+}$(calc. for $\mathrm{C}_{64} \mathrm{H}_{58} \mathrm{~F}_{12} \mathrm{~N}_{4} \mathrm{Si}_{2} \mathrm{~S}_{4}=1294.2891$ ).

\section{Spectroscopic characterization of $1(c, o)$}

Compound $\mathbf{1}(\mathbf{c}, \mathbf{o})$ was generated by the irradiation $(\lambda=436 \mathrm{~nm})$ of a $d^{12}$-cyclohexane solution of $\mathbf{1}(\mathbf{o , o})$ for $30 \mathrm{~min}$. Selected data: ${ }^{1} \mathrm{H}$ NMR (500 MHz, $d^{12}$-cyclohexane): $\delta 8.48$ and $8.46(2 \times \mathrm{d}$, $\left.{ }^{3} J=5 \mathrm{~Hz}, 2 \mathrm{H}, \mathrm{Py}^{6}\right), 8.49$ and $8.42\left(2 \times \mathrm{s}, 2 \mathrm{H}, \mathrm{Py}^{3}\right), 7.58(\mathrm{~d}$, $\left.{ }^{3} J=15.7 \mathrm{~Hz}, 1 \mathrm{H},=\mathrm{CH}(\mathbf{c})\right), 7.25(\mathrm{~s}, 1 \mathrm{H}, \operatorname{thio}(\mathbf{o})), 7.21(\mathrm{~s}, 1 \mathrm{H}$, thio(o)), 7.09 and $6.95\left(2 \times \mathrm{dd},{ }^{3} J=5.1 \mathrm{~Hz}, 2 \mathrm{H}, \mathrm{Py}^{5}\right), 6.92(\mathrm{~d}$, $\left.{ }^{3} J=15.9 \mathrm{~Hz}, 1 \mathrm{H},=\mathrm{CH}(\mathbf{o})\right), 6.70(\mathrm{~s}, 1 \mathrm{H}$, thio $(\mathbf{c})), 6.33(\mathrm{~s}, 1 \mathrm{H}$, thio(c)), 2.97 and $2.96\left(2 \times \mathrm{s}, 12 \mathrm{H}, \mathrm{NMe}_{2}\right)$, and 2.04 and 1.96 $(2 \times \mathrm{s}, 6 \mathrm{H}, \mathrm{Me})$.

\section{X-Ray diffraction study of $1(0,0)$}

Single crystals for $\mathrm{X}$-ray diffraction studies were grown by the slow evaporation of a $\mathrm{CH}_{2} \mathrm{Cl}_{2}$ solution of complex $\mathbf{1}(\mathbf{0}, \mathbf{0})$ at $20{ }^{\circ} \mathrm{C}$. The sample $(0.32 \times 0.28 \times 0.28 \mathrm{~mm})$ was studied on an Oxford Diffraction Xcalibur Saphir 3 diffractometer with graphite monochromatized Mo- $\mathrm{K}_{\alpha}$ radiation. $\mathrm{C}_{64} \mathrm{H}_{58} \mathrm{~F}_{12} \mathrm{~N}_{4} \mathrm{~S}_{4} \mathrm{Si}_{2}$, $M=1295.6$, monoclinic, $P 2_{1} / n, a=10.45582(5)$, $b=19.8097(9), \quad c=14.9154(7) \AA, \quad \beta=100.277(4)^{\circ}$, $V=3040.5(2) \AA^{3}, Z=2, \rho_{\text {calc }}=1.415 \mathrm{~g} \mathrm{~cm}^{-3}, \mu_{\text {Mo-K }}=$ $2.77 \mathrm{~mm}^{-1}$, reflections collected $=21731$, independent reflections $=6585$, independent reflections with $I>2 \sigma(I)=$ $4381, R 1$ (all data) $=0.1086$ and $\mathrm{w} R 2($ all data $)=0.2618 . \dagger$

\section{References}

1 (a) M. Irie, Chem. Rev., 2000, 100, 1685; (b) H. Tian and S. Yang, Chem. Soc. Rev., 2004, 33, 85; (c) F. M. Raymo and M. Tomasulo, J. Phys. Chem. A, 2005, 109, 7343.

2 Selected examples: (a) Y.-C. Jeong, S. I. Yang, K.-H. Ahn and E. Kim, Chem. Commun., 2005, 2503; (b) G. Jiang, S. Wang, W. Yuan, L. Jiang, Y. Song, H. Tian and D. Zhu, Chem. Mater., 2006, 18, 234; (c) M.-Q. Zhu, L. Zhu, J. J. Han, W. Wu, J. K. Hurst and A. D. Q. Li, J. Am. Chem. Soc., 2006, 128, 4303; (d) S.-J. Lim, J. Seo and S. Y. Park, J. Am. Chem. Soc., 2006, 128, 14542; (e) Z. Zhou, S. Xiao, J. Xu, Z. Liu, M. Shi, F. Li, T. Yi and C. Huang, Org. Lett., 2006, 8, 3911; (f) T. Fukaminato, T. Umemoto, Y. Iwata, S. Yokojima, M. Yoneyama, S. Nakamura and M. Irie, J. Am. Chem. Soc., 2007, 129, 5932; (g) L. Zhu, W. Wu, M.-Q Zhu, J. J. Han, J. K. Hurst and A. D. Q. Li, J. Am. Chem. Soc., 2007, 129, 3524; (h) T. A. Golovkova, D. Kozlov and D. C. Neckers, J. Org. Chem., 2005, 70, 5545.

3 Selected examples: (a) A. Fernàndez-Acebes and J.-M. Lehn, Chem.-Eur. J., 1999, 5, 3285; (b) V. W.-W. Yam, C.-C. Ko and N. Zhu, J. Am. Chem. Soc., 2004, 126, 12734; (c) R. T. F. Jukes, V. Adamo, F. Hartl, P. Belser and L. De Cola, Inorg. Chem., 2004, 43, 2779; (d) P. H.-M. Lee, C.-C. Ko, N. Zhu and V. W.-W. Yam, J. Am. Chem. Soc., 2007, 129, 6058.

4 M. Giraud, A. Léaustic, R. Guillot, P. Yu, P. G. Lacroix, K. Nakatani, R. Pansu and F. Maurel, J. Mater. Chem., 2007, 17, 4414 .

5 (a) O. Maury, L. Viau, K. Sénéchal, B. Corre, J.-P. Guégan, T. Renouard, I. Ledoux, J. Zyss and H. Le Bozec, Chem.-Eur. $J ., 2004,10,4454 ;$ (b) O. Maury and H. Le Bozec, Acc. Chem. Res., 2005, 38, 691.

6 V. Aubert, V. Guerchais, E. Ishow, K. Hoang-Thi, I. Ledoux, K. Nakatani and H. Le Bozec, Angew. Chem., Int. Ed., 2008, 47, 577.

7 For examples of DTE derivatives substituted at the 2-positions of the thiophene rings, see: $(a)$ T. Kodani, K. Matsuda, T. Yamada, S. Kobatake and M. Irie, J. Am. Chem. Soc., 2000, 122, 9631; (b) N. Tanifuji, M. Irie and K. Matsuda, J. Am. Chem. Soc., 2005, 127, 13344; (c) A. Peters, R. McDonald and N. R. Branda, Chem. Commun., 2002, 2274; (d) K. Yumoto, M. Irie and K. Matsuda, Org. Lett., 2008, 10, 2051.

8 (a) T. Yamada, S. Kobatake, K. Muto and M. Irie, J. Am. Chem. Soc., 2000, 122, 1589; (b) H. Choi, H. Lee, Y. Kang, E. Kim, S. O. Kang and J. Ko, J. Org. Chem., 2005, 70, 8291.

9 O. Maury, J.-P. Guégan, T. Renouard, A. Hilton, P. Dupau, N. Sandon, L. Toupet and H. Le Bozec, New J. Chem., 2001, 25, 1553.

10 For examples of multi-DTE-based systems with partial photocyclization, see: (a) T. Kawai, T. Sasaki and M. Irie, Chem. Commun., 2001, 711; (b) H. Tian, B. Chen, H. Tu and K. Müllen, Adv. Mater., 2002, 14, 918; (c) I. Jung, H. Choi, E. Kim, C.-H. Lee, S. O. Kang and J. Ko, Tetrahedron, 2005, 61, 12256. 